\title{
Improved Coordinated Control of AVM based Multi-Terminal HVdc System using Steady-State Analysis
}

\author{
Muhammad Zain Yousaf, Muhammad Arslan Shahid, Danista Khan and Saqib Khalid \\ Department of Electrical Engineering \\ The University of Lahore, Lahore, Pakistan \\ mzainy1@gmail.com, arslan.shahid@ee.uol.edu.pk, danista91@gmail.com and \\ saqib.khalid@ee.uol.edu.pk
}

\begin{abstract}
Modular Multilevel Converter (MMC) with the addition of average voltage model (AVM) has increased the efficiency, performance and scalability for voltage source converter (VSC) within multi-terminal high voltage direct current (MT-HVdc) network. When this technology is integrated into the large HVdc transmission system, electromagnetic-transients (EMT) complicates the study of transient's states. Unlike complex modelling, a simple and better understanding of the AVM in VSC stations helps to improve the dynamic control performance in the large transmission system hence, improving steady and transient states. This paper presents the solution, by using state space analysis of a four terminal test grid, to optimize control parameters of VSC stations. In order to validate the desirable performance of AVM under dynamic states, practical scenarios have been simulated using PSCAD/EMTDC software. Simulation results are presented and its state-space analysis is also studied.
\end{abstract}

Keywords: Power System Control; High Voltage; Average Value Model; Voltage Source Converter; HVdc; State-Space; Steady-State Analysis; Coordinated operation and Control; Transmission.

\section{Introduction}

$\mathrm{HVdc}$ is preferred as the suitable transmission system than alternating current (ac) for bulk power transfer [1-2]. The development of controllable semiconductor switches and voltagesource converter (VSC) technologies are rapidly expanding within the fields of high-voltage direct current (HVdc) and flexible ac transmission systems (FACTS). Presently, the topology which persists in controlled converter technology for an efficient response against the rise of short circuit faults across ac and de side is modular multilevel converters (MMC), with fourquadrant converter modules [3-6]. MMC technology has various advantages such as low switching frequency, high efficiency and excellent output voltage waveforms [7-8]. The major advantage is that all switches have reduced frequency of switching which results in minimum switching losses [9]. Advancement in VSC and MMC technologies are leading to reduce undesirable impacts in the power systems. MMC technology was first introduced in Trans Bay Cable Transmission Project (California, USA) [1].

In MMC-HVdc, scalability to higher voltages is easily achieved and reliability is improved by increasing the number of submodules (SMs) [10]. Previously, detailed models (DM) for MMC-HVdc systems were used which include the representation of thousands of semiconductor switches that use small numerical integrated time steps for fast switching events accurately. However, computational burden introduced by these models highlights the need to develop simplified models which provide similar behavior and efficient dynamic response. These simplified models are known as mean or average-value models (AVMs). Their main purpose is to replicate the average response of switching devices and converters, and controls them by using simplified functions and controlled sources [11-12]. They require significantly less computational resources and use larger integrated time steps leading to much faster computations 
[13]. AVMs have been successfully developed for wind generation technologies [14-15], which are usually connected to the onshore AC systems.

MMC superiority against its predecessor i.e. two or three level VSCs helps to replace them for the HVdc applications. Now, MMC with the addition of AVMs has decreased the complexities and still keeping the level of efficiency for steady and transient states [16-17]. But when this technology integrates into the large and complex system, it complicates the study of transient's states and hence, effecting the performance of controller under steady and transient states [18].

The main contribution of this paper is to present state-space analysis of a generic multiterminal HVdc grid, which then helps to improve the controller limits in AVM-VSC technology. In the VSC controller, these limits can be improved by optimizing the values of proportional integral (PI), which helps to get the correct response under dynamic states [18]. The optimization process is based on combining the equations describing different parts of the transmission grid using state-space analysis. As a result, simplified model for an HVdc test grid can be obtained. This analysis further helps to optimize controller limits and hence, improving the steady-state and transient's response under dynamic conditions.

Usually hit and trial method is used to tune controller parameters, but this method cannot optimize PI values in the controller of VSC technology because the VSCs have non-linear nature [19-20]. This paper presents the solution by using state-space analysis that helps to optimize PI values in the VSC controller. The suggested solution can enhance VSC performance under dynamic states. Further, to validate the performance of the proposed solution, dynamic simulations for a four-terminal test grid are developed in PSCAD. Two case studies with the simulations are included; first include change in wind power and second is change of load demand at ac side. Results of proposed solution are also compared with classical hit and trial method.

This paper is organized as; Section II with a detailed description of the proposed AVM-VSC$\mathrm{HVdc}$ test system. It also includes AVM and its mathematic derivation. The state-space model of a generic multi-terminal HVdc based on AVM is given in Section III. Section IV comprises the detailed explanation of optimizing the control structure using state-space analysis. The results obtained from simulations in order to understand the dynamic response of AVM based four terminal MMC-VSC-HVdc system are presented in Section V. Finally, the conclusions are made in Section VI.

\section{Proposed MMC-VSC HVdc Test Topology}

Figure. 1, shows the schematic diagram of four terminal AVM based MMC-VSC station in an $\mathrm{HVdc}$ system. Transmission lines are bi-polar in nature which are connected via positive and negative dc voltages. In order to mimic a practical dc system, $100 \mathrm{mH}$ dc inductor is introduced in each line. However, dc inductors do not come with dc grids faults protection. The rating of the dc test system is presented in Table 1 .

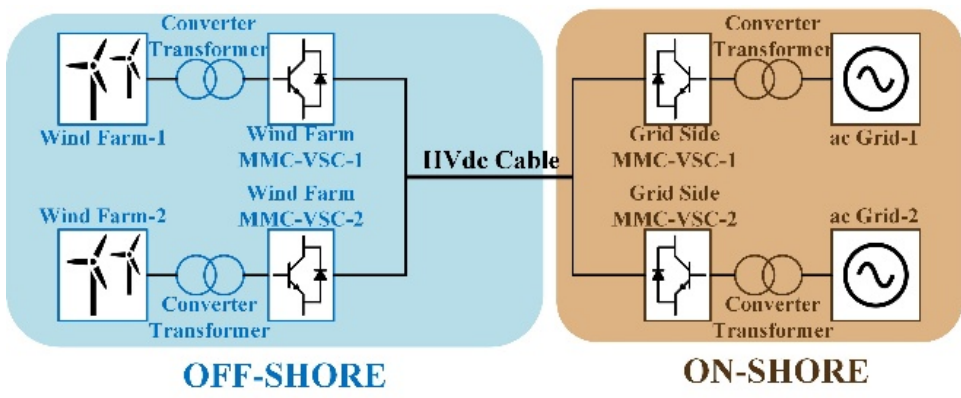

Figure 1. Schematic diagram of four terminal MMC-HVdc transmission system 
Table 1. Parameters of the MTdc grid

\begin{tabular}{|c|c|c|c|}
\hline Model & $\begin{array}{c}\text { Rated voltage } \\
{[\mathbf{k V}]}\end{array}$ & Impedance & Specifications \\
\hline AC networks & $33 \mathrm{kV}$ & $0.0014+\mathrm{j} 0.016 \mathrm{pu}$ & $1000 \mathrm{MVA}$ \\
\hline Wind Farms & $245 \mathrm{kV}$ & $0.002+\mathrm{j} 0.0101 \mathrm{pu}$ & $1000 \mathrm{MVA}$ \\
\hline Phase reactor & $420 \mathrm{kV}$ & $0.011+\mathrm{j} 0.13 \mathrm{pu}$ & - \\
\hline dc capacitor & $420 \mathrm{kV}$ & $\begin{array}{c}\text { Two } 1450 \mu \mathrm{F} \\
\text { capacitor in series }\end{array}$ & $100 \mathrm{~km}$ distance \\
\hline
\end{tabular}

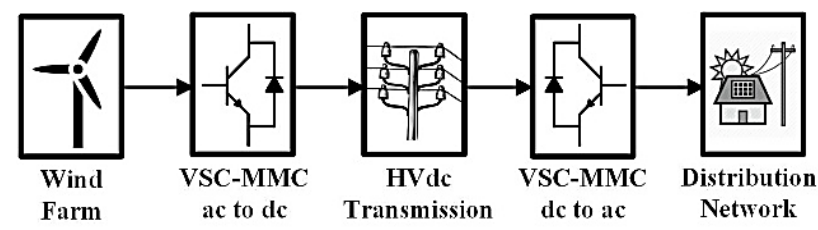

Figure 2. Block diagram of HVdc power system

The block diagram of HVdc power system showing the placement of MMC is represented in Figure. 2. The AVM based MMC-VSC-HVdc test system is presented in Figure. 3, which includes sub modules (SM) in each phase. Each SM is comprised of a capacitor, a pair of IGBTs (IGBT-1 and IGBT-2) and two switches (Z1 and Z2). Normally, only one switch is in ON state at a time. When IGBT-1 is ON, IGBT-2 is in OFF state and the voltage of $n^{\text {th }}$ SM becomes $V_{S}$. Similarly, when IGBT-2 is in ON state, IGBT-1 is in OFF state and the voltage of $n^{\text {th }}$ SM becomes zero. For the balancing of currents flow in each arm of the phase and to limit the fault current arm, reactor $\mathrm{L}_{\mathrm{S}}$ is used [21].

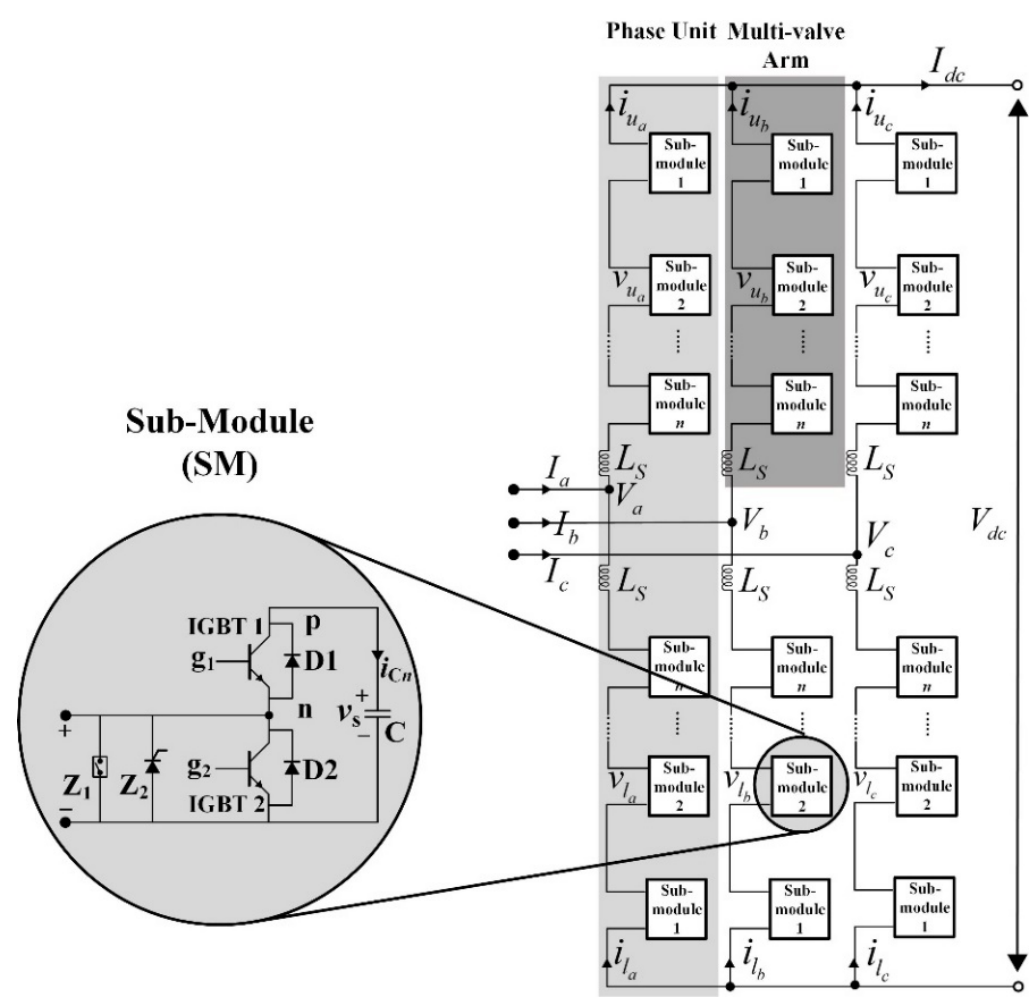

Figure 3. Detailed MMC topology and MMC sub-module 
The equivalent model of switching IGBTs is illustrated in Figure. 4, which consists of two non-ideal diodes in parallel and series combination with $\mathrm{RC}$ circuit. The non-ideal diodes are using the classical function of diodes to model as non-linear resistance. When SM in MMCs fails to perform its normal operation, the ideal fast speed switch $Z_{1}$ bypasses the current, and adds the safety and reliability. $Z_{2}$ is a press-pack thyristor that immunes the MMC and protects its lines from excessive fault currents. Due to a fault, dc currents flow from the ac to dc side through freewheeling diode. This free-wheeling diode is incapable of tolerating big rise in current, therefore, during the fault, switch $Z_{2}$ changes the fault current direction to cause it to flow through thyristor instead of free-wheeling diode [22].

For achieving dynamic performance and power flow control, it is important to understand the model of AVM in VSC station. The next sub-section presents the proposed AVM based MMCVSC-HVdc system with detailed description and fundamental design.

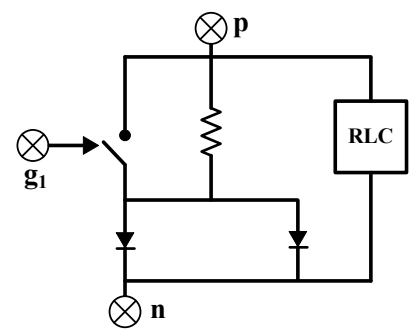

Figure 4. IGBT valve

\section{A. Ac-side Representation of the Average Value Model}

For an AVM, the behavior of MMC is represented using controlled current and voltage sources. AVM is similar to the DM as shown in Figure. 3, but attain reference voltages from the inner current control section, where phase and magnitude are separately controlled. Voltage equations for upper and lower arm are illustrated below and are obtained from MMC diagram in Figure. 3, for each phase ' $\mathrm{x}$ ', where, $\mathrm{x}=\mathrm{a}$, b or c.

For upper arm, the voltage equation is:

$$
V_{u_{x}}=V_{u_{x}}^{S M}-L_{S} \frac{d i_{u_{x}}}{d t}
$$

Where, $V_{u_{x}}$ is the voltage at the upper arm including reactor $L_{S}$ voltage, $V_{u_{x}}^{S M}$ is the voltage across the SM and $i_{u_{x}}$ is the circulating current in each arm or phase. Similarly, for lower arm the voltage equation is:

$$
V_{l_{x}}=V_{l_{x}}^{S M}-L_{S} \frac{d i_{l_{x}}}{d t}
$$

Where, $V_{u_{x}}, V_{u_{x}}^{S M}$ and $i_{u_{x}}$ are similar quantities for lower arm.

$$
\begin{aligned}
& V_{u_{x}}^{S M}=\sum_{k=1}^{N_{a r m}}\left(S_{u_{j_{k}}} V C_{u_{j_{k}}}\right) \\
& V_{l_{x}}^{S M}=\sum_{k=1}^{N_{a r m}}\left(S_{l_{j_{k}}} V C_{l_{j_{k}}}\right)
\end{aligned}
$$

It has a functional relation to the number of capacitors that are turned $\mathrm{ON}$, as shown in (3) for upper arm and in (4) for lower arm, where, $S_{u_{j_{k}}} / S_{l_{j_{k}}}$ gives ON/OFF state for each capacitor in upper and lower arm respectively. Phase voltage $V_{x}$, and the voltage of a SM for upper and lower arm are shown in terms of output voltage $V_{d c}$ in (5), (6) and (7). 


$$
\begin{aligned}
& V_{x}=-V_{u_{x}}+\frac{V_{d c}}{2}=V_{l x}-\frac{V_{d c}}{2} \\
& V_{u_{x}}^{S M}=-V_{x}+L_{S} \frac{d i_{u_{x}}}{d t}+\frac{V_{d c}}{2} \\
& V_{l_{x}}^{S M}=V_{x}+L_{S} \frac{d i_{l_{x}}}{d t}+\frac{V_{d c}}{2}
\end{aligned}
$$

In each phase, the currents for each arm is same. The circulating current equations are illustrated in (8) and (9). The ac side of AVM is presented in Figure. 5.

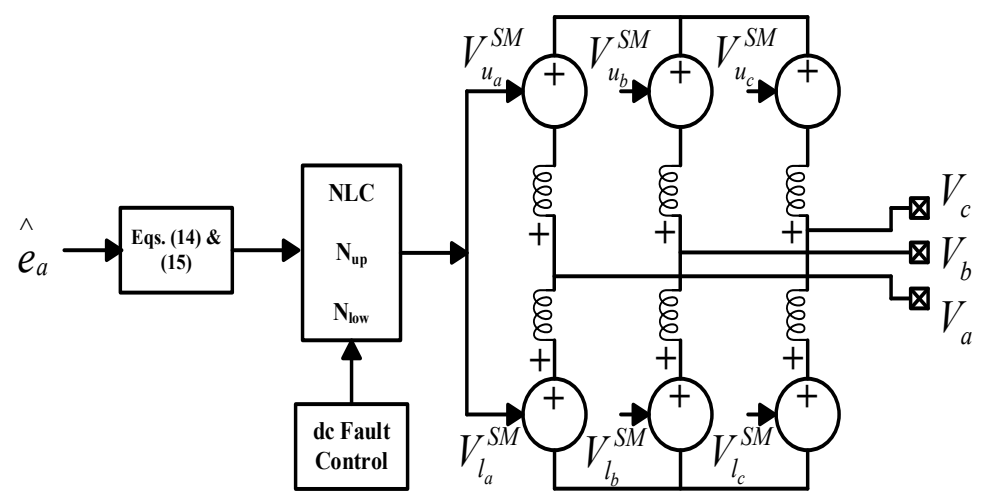

Figure 5. Representation of ac-side in AVM

$$
\begin{aligned}
& i_{u_{x}}=\frac{i_{x}}{2}+\frac{I_{d c}}{3}+i_{z_{x}} \\
& i_{Z_{x}}=\frac{i_{u_{x}}+i_{l_{x}}}{2}-\frac{I_{d c}}{3}
\end{aligned}
$$

Average modules assume that all capacitors voltages are balanced and circulated $2^{\text {nd }}$ harmonic currents are zero.

$$
\begin{aligned}
& V_{l_{x}}=V_{l_{x}}^{S M}-L_{S} \frac{d i_{l_{x}}}{d t} \\
& i_{z_{a}}+i_{z_{b}}+i_{z_{c}}=0 \\
& V_{x}=\frac{L_{S}}{2} \frac{d i_{l_{x}}}{d t}+e_{x}
\end{aligned}
$$

In (12) $e_{x}$ is expressed as:

$$
e_{x}=\frac{V_{l_{x}}^{S M}-V_{u_{x}}^{S M}}{2}
$$

Putting values from (10) and (12) into (7) gives:

$$
V_{u_{x}}^{S M}=-\left(V_{x}-\frac{L_{S}}{2} \frac{d i_{x}}{d t}\right)+\frac{V_{d c}}{2}=-e_{x}+\frac{V_{d c}}{2}
$$

The lower arm equation yields same as in (14):

$$
V_{l_{x}}^{S M}=\left(V_{x}-\frac{L_{S}}{2} \frac{d i_{x}}{d t}\right)+\frac{V_{d c}}{2}=e_{x}+\frac{V_{d c}}{2}
$$




\section{B. Dc-side Representation of the Average Value Model}

In AVM, the model of dc-side is based on the concept that power of ac side is equivalent to the power of dc-side and expressed as:

$$
\begin{aligned}
& P_{a c}=P_{d c}+P_{l o s s} \\
& \sum_{x=a, b, c} e_{x} i_{x}=V_{d c} I_{d c}+P_{l o s s}
\end{aligned}
$$

The modulation index is expressed in (18) by terms of its definition.

$$
m_{x}=2 \frac{e_{x}}{V_{d c}}
$$

Also, revising of the power balance of (17) as:

$$
\frac{P_{a c}}{V_{d c}}=\frac{1}{2} \sum_{x=a, b, c} m_{x} i_{x}=I_{d c}+\frac{P_{l o s s}}{V_{d c}}
$$

The loss of current in converter is defined by function in (20).

$$
\begin{gathered}
I_{\text {loss }}=\frac{P_{\text {loss }}}{V_{d c}}=R \frac{I_{c}{ }^{2}}{V_{d c}} \\
I_{c}=\frac{1}{2} R \sum_{x=a, b, c} m_{x} i_{x}
\end{gathered}
$$

Where, $I_{c}$ is the equivalent dc current, expressed in (21), which includes losses from converters as well. The dc current can be calculated using (20) and (21), as shown in (22).

$$
I_{d c}=I_{c}-I_{\text {loss }}
$$

The value of $R$ represents equivalent resistance. While calculating the value of $R$, switching frequency and converter losses should be taken in consideration because these values depend on the modulation technique. $R$ is selected using the information from DM of MMC losses, but the parallel resistance of the MMC at dc side does not allow modelling of current dependent losses. These losses depend on dc voltage only, so, the MMC losses can be modelled using (20). However, in AVM based MMC, dc side is represented by current sources, which is based on two current controlled models and depends on circulating current $I_{c}$ as shown in Figure. 6.

Dynamic repose of AVM is faster and accurate due to unchanged parameters of the control section. When fault occurs in DM, $Z_{2}$ is shortened in all sub-modules. This converts the MMC into six-pulse bridge diode converter, presented in Figure 3.

In order to have same protection in the AVM against short-circuit fault of voltage-controlled sources, $C_{e}$ provides the solution by disconnecting itself from sub-modules during the fault. From Figure 6, in AVM, series thyristor is added to dc side, that pushes dc current to flux from ac side to de side.

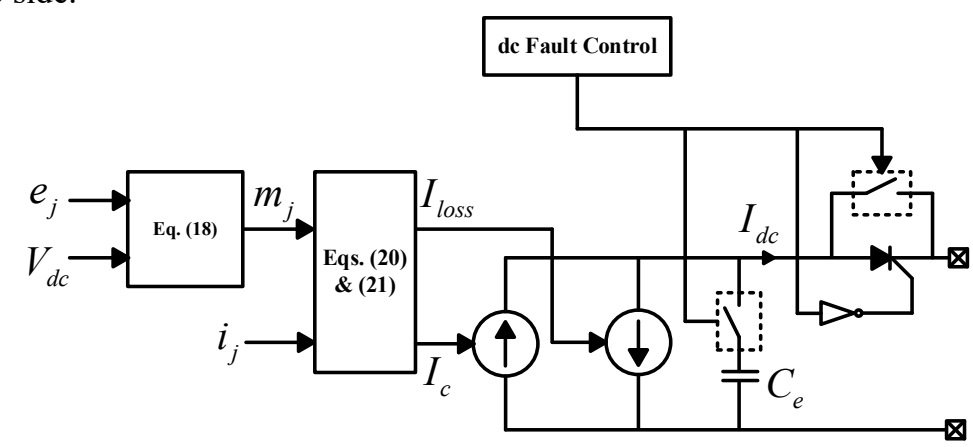

Figure 6. De section of AVM in MMC 


\section{Multi-Terminal State-Space Representation of the Test System}

A simple steady-space state model of HVdc grid helps to describe dynamic response of the system. It can help to choose optimal limits and choose correct parameters. For state-space analysis, a simplified circuit modeling is required. The circuit modelling explained in the next sub-section, contributes in the state-space analysis for the proposed test system.

\section{A. Equivalent Circuit Model}

An equivalent model is obtained by connecting nodes and branches. A four terminal HVdc gird with two offshore wind farms and two on shore grids is presented in Figure. 7.

The variable constraints shown in Figure. 7 are described as follows:

- $R_{1}$ and $R_{3}$ represent branch resistance on transmission lines of the grid.

- $L_{1}, L_{2}$ and $L_{3}$ represent branch inductances on transmission lines of the grid.

- $I_{L 1}, I_{L 2}, I_{L 3}, I_{C 1}, I_{C 2}, I_{C_{m+p+1}}$ and $I_{C_{m+p+2}}$ are currents flowing through different inductors and capacitors.

- $C_{1}, C_{2}, C_{m+n+1}$ and $C_{m+n+2}$ represent the equivalent capacitances of the capacitors which are connected in parallel to the grid.

- $E_{1}, E_{2}, E_{m+n+1}$ and $E_{m+n+2}$ represent the voltages across the capacitors which are in parallel to the current sources.

- $P_{1}, P_{2}, P_{m+n+1}$ and $P_{m+n+2}$ represent the power supplying by the different converters which are connected to the respective grids.

- $I_{1}, I_{2}, I_{m+n+1}$ and $I_{m+n+2}$ represent currents from current sources in the HVdc grids.

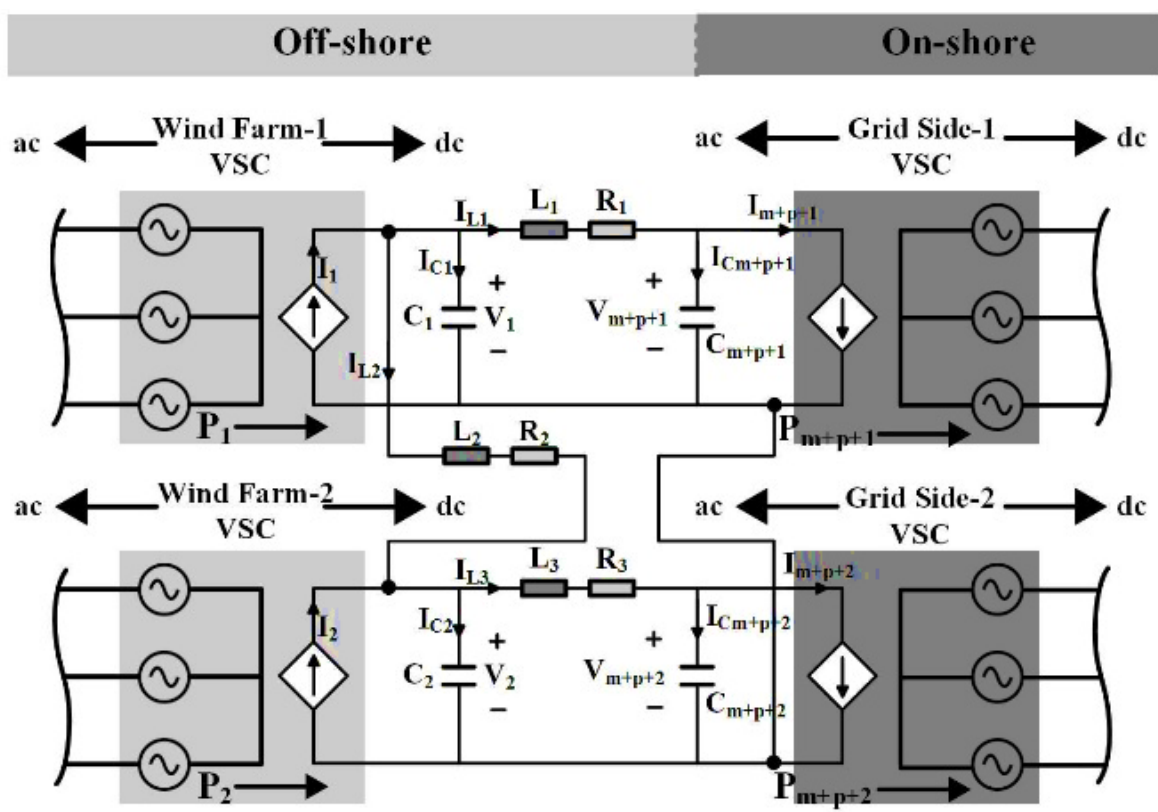

Figure 7. Four terminal HVdc grid

\section{B. State-Space Representation of Four Terminal HVdc System}

Dynamic performance of the HVdc grid systems can be described using first-order differential equations. These differential equations are acknowledged as the representation of state-space and expressed in the form as in (23), (24) and (25). 
Dynamic model is:

$$
\frac{d x_{1}}{d t}=A x+B_{w} w+B_{u} u
$$

Non-controlled output equation is:

$$
z=C_{z} x
$$

Controlled output equation is:

$$
y=C_{y} y
$$

Where, $x$ represents state vector, $\dot{x}$ represents derivative of state vector, $u$ represents vector of a controlled input, $w$ represents vector of a non-controlled input, $y$ represents controlled output vector, $z$ represents non-controlled output vector, $A$ represents state of matrix, $B_{u}$ represents controlled input values in a matrix, $B_{w}$ represents non-controlled input in a matrix, $C_{y}$ represents controlled output vector in a matrix and $C_{z}$ represents controlled output values in a matrix.

The equivalent model presented in Figure. 7, is applicable to the four terminal HVdc test system illustrated in Figure. 1. The four terminal HVdc system consists of two off-shore wind farm converters (Wind Farm 1 VSC and Wind Farm 2 VSC) and two on-shore grid side converters (Grid Side 1 VSC and Grid Side 2 VSC). The three branches are representing cables that are interconnecting the converters and has two input and two output nodes. The capacitance of nodes and their corresponding branches are represented by the capacitances added, as shown in Figure.7.

Applying first order differential equation to the four terminal HVdc system results in the equations from (26) to (36).

$$
\begin{aligned}
& \frac{d V_{1}}{d t}=\frac{1}{C_{1}} I_{C_{1}} \\
& \frac{d V_{2}}{d t}=\frac{1}{C_{2}} I_{C_{2}} \\
& \frac{d V_{3}}{d t}=\frac{1}{C_{3}} I_{C_{3}} \\
& \frac{d V_{4}}{d t}=\frac{1}{C_{4}} I_{C_{4}} \\
& \frac{d I_{L_{1}}}{d t}=\frac{1}{L_{1}}\left(-R_{1} I_{L_{1}}+V_{1}-V_{3}\right) \\
& \frac{d I_{L_{2}}}{d t}=\frac{1}{L_{2}}\left(-R_{2} I_{L_{2}}+V_{1}-V_{2}\right) \\
& \frac{d I_{L_{3}}}{d t}=\frac{1}{L_{3}}\left(-R_{3} I_{L_{3}}+V_{2}-V_{4}\right) \\
& I_{C_{1}}=I_{1}-I_{L_{1}}-I_{L_{2}} \\
& I_{C_{2}}=I_{2}-I_{L_{3}}+I_{L_{2}} \\
& I_{C_{3}}=-I_{3}+I_{L_{1}} \\
& I_{C_{4}}=-I_{4}+I_{L_{3}}
\end{aligned}
$$

Equation (37) shows the variables which are enough to define the state of the system including four capacitors and three inductors. 


$$
x=\left[V_{C_{1}} V_{C_{2}} V_{C_{3}} V_{C_{4}} I_{L_{1}} I_{L_{2}} I_{L_{3}}\right]^{T}
$$

Input and output of system is defined into following matrices.

$$
w=\left[I_{1} I_{2}\right]^{T}, u=\left[I_{3} I_{4}\right]^{T}, z=\left[V_{1} V_{2}\right]^{T}, y=\left[V_{3} V_{4}\right]^{T}
$$

Since, wind farms are injecting all the available power to the grid sides and a rush of current is expected. So, the droop control at the grid side terminals helps to control the dc voltage and stabilizes it. In (38), $w$ is vector of currents and $u$ is control input that contains vector currents of the grid side 1 and grid side 2 respectively. $V_{1}$ and $V_{2}$ represent voltages that are input to the controller. $V_{3}$ and $V_{4}$ represent the reference voltages, for $V_{1}$ and $V_{2}$, to be maintained. Matrices for state-space representation are expressed in (39), (40), (41), (42) and (43).

$$
\begin{aligned}
& A=\left[\begin{array}{ccccccc}
0 & 0 & 0 & 0 & -1 / C_{1} & -1 / C_{1} & 0 \\
0 & 0 & 0 & 0 & 0 & 1 / C_{2} & -1 / C_{2} \\
0 & 0 & 0 & 0 & 1 / C_{3} & 0 & 0 \\
0 & 0 & 0 & 0 & 0 & 0 & 1 / C_{4} \\
1 / L_{1} & 0 & -1 / L_{1} & 0 & -R_{1} / L_{1} & 0 & 0 \\
1 / L_{2}-1 / L_{2} & 0 & 0 & 0 & -R_{2} / L_{2} & 0 \\
0 & 1 / L_{3} & 0 & -1 / L_{3} & 0 & 0 & -R_{3} / L_{3}
\end{array}\right] \\
& B_{w}=\left[\begin{array}{cc}
1 / C_{1} & 0 \\
0 & 1 / C_{2} \\
0 & 0 \\
0 & 0 \\
0 & 0 \\
0 & 0 \\
0 & 0
\end{array}\right] \\
& B_{u}=\left[\begin{array}{cc}
0 & 0 \\
0 & 0 \\
-1 / C_{3} & 0 \\
0 & -1 / C_{4} \\
0 & 0 \\
0 & 0 \\
0 & 0
\end{array}\right] \\
& C_{z}=\left[\begin{array}{lllllll}
1 & 0 & 0 & 0 & 0 & 0 & 0 \\
0 & 1 & 0 & 0 & 0 & 0 & 0
\end{array}\right] \\
& C_{y}=\left[\begin{array}{lllllll}
0 & 0 & 1 & 0 & 0 & 0 & 0 \\
0 & 0 & 0 & 1 & 0 & 0 & 0
\end{array}\right]
\end{aligned}
$$

\section{Optimization of the Control Structure using State-Space Analysis}

This section of the paper describes the methodology to optimize the control parameters of the VSC station using state-space analysis. The analysis done in previous section helps to choose right control parametric values which in return can improve the dynamic response of the system. In order to validate the results, control structure of the VSC studied in the sub-sequent section gives the optimized parametric values using state-space analysis.

\section{A. Control Structure of VSC Based MMC}

The control diagram shown in Figure. 8 is the controller for ac voltage of the offshore windfarms (Wind Farm-1 and Wind Farm-2). The voltages are kept constant at a particular magnitude with $50 \mathrm{~Hz}$ frequency using a proportional integral (PI) controller. PI controller minimizes the error i.e. difference between actual and reference RMS voltages at the terminals of wind farms, represented in (44).

$$
\text { Error }=V_{W F}-V_{W F}^{*}
$$


Where, $\mathrm{V}_{\mathrm{WF}}$ is actual RMS voltage and $\mathrm{V}_{\mathrm{WF}}{ }^{*}$ is reference RMS voltage.

The control diagram illustrated in Figure. 9 presents the improved proportional droop control which allows the coordination of de voltage between grid side MMC-VSC-1 and MMC-VSC-2. $\mathrm{V}_{\mathrm{g}}{ }^{*}$ and $\mathrm{P}^{*}$ are the dc reference voltage and active power in per unit respectively. ' $\mathrm{K}$ ' is the slope of droop characteristics and the grid side converter dc voltage, with zero power, are represented by $\mathrm{V}_{\mathrm{g}}$ in per unit.

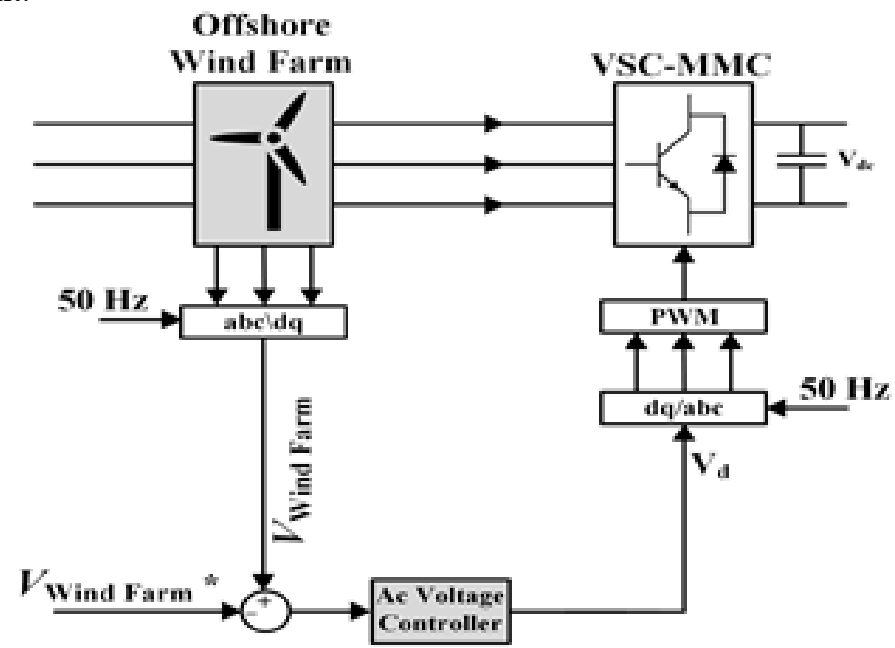

Figure 8. Ac voltage controller schematic for wind farms

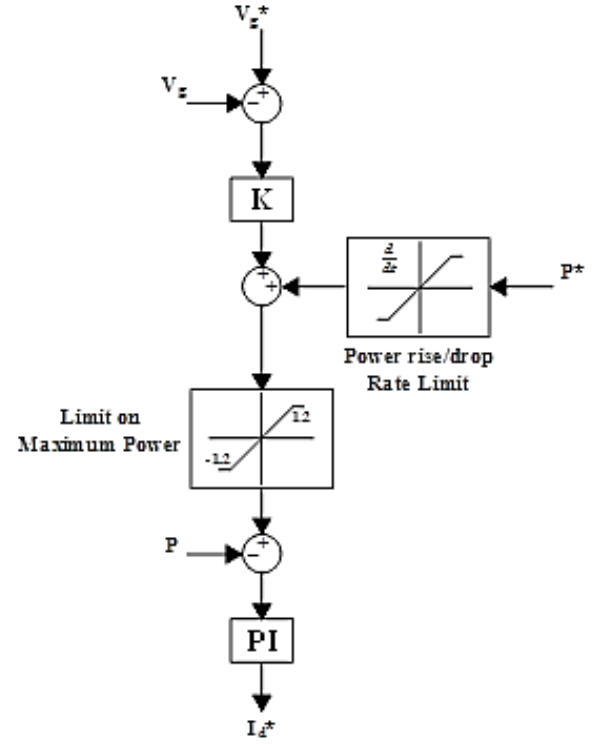

Figure 9. Improved proportional droop control

The control scheme in Figure. 10 shows the control structure of the VSC base multi-terminal $\mathrm{HVdc}$ system. Differential quadrature (d-q) method is used to regulate either dc voltage or active power and reactive power or ac voltage. The d-components are in charge of active power or dc voltage control while the q-components are responsible for reactive power or ac voltage level. From the three-phase line, currents are converted to two dimensions for the sake of simplicity of the system. Taking in to account the d-q frame, the inner current controller incorporates the PI controllers which are responsible for the reference currents and manage the reference voltage for the VSCs. Summation of the output of PI control, $\mathrm{V}_{\mathrm{qg}}$ from phase-locked loop (PLL abc to dq 
transformation) and compensating term $-\mathrm{L}_{\text {wid }}$ for decoupling of the $\mathrm{d}$ and $\mathrm{q}$-axis control results in the axis-q voltage form. The two axis components $\mathrm{V}_{\mathrm{q}}$ and $\mathrm{V}_{\mathrm{d}}$ are fed into the d-q-to-abc transformation block to perform inverse park transformation and finally the resulting PWM is fed to MMC-VSC at the grid side.

\section{B. Optimization of the Control Structure of VSC Stations}

State-space analysis helps to control variables and values inside the control structure of the VSC technology, which improve the PI values of controller. The two-axis components generate parametric equation as shown below for inner and outer sections of the controller in the VSC station

For inner control section [23-24]

$$
Z_{\text {ICS }}=\int_{0}^{t} T .\left|i_{d}-i_{\text {dref }}\right| d t
$$

For outer control section [22], [24]

$$
\begin{aligned}
Z_{o c s}= & \int_{0}^{t} T \cdot\left|P-P_{r e f}\right| d t \\
Z_{o c s}= & \int_{0}^{t} T \cdot\left|V-V_{r e f}\right| d t
\end{aligned}
$$

The dynamic response of the multi-terminal (MT) HVdc system under any disturbance, depends upon the performance of the controller. In AVM-VSC-HVdc system, the values of the PI parameters constituent an integral part of the controller. The PI controller is a generic feedback controller which is extensively being used at industrial scale in the field of control. Normally, it is required for non-integrating procedures, which means that any process would return to the same output for the given set of inputs and disturbances. In order to tune PI parameters, Internal Model Control (IMC) and Integral of Time-weighted Absolute Error (ITAE) methods are used. In this research, ITAE method has been implemented due to its supremacy on the IMC [30]. In this paper, equation (45), (46) and (47) need minimization using ITEA method. State-space analysis helps to give ideal range for the two-dimensional values of current and voltages, which can reduce differences in the reference and real values in (45), (46) and (47). Thus, approaching towards optimal values of PI using minimization.

Table 2. PI Controller Parameters

\begin{tabular}{|c|c|c|}
\hline PI Controller & Kp & Ki \\
\hline Windfarm ac voltage controller & 0.4 & 35.00 \\
\hline Active power controller & 0.35 & 85.25 \\
\hline Reactive power controller & 0.35 & 85.25 \\
\hline d-axis controller & 0.45 & 0.070 \\
\hline q-axis controller & 0.48 & 0.670 \\
\hline Gridside dc voltage controller & 0.38 & 82.75 \\
\hline
\end{tabular}

Earlier PI values tuned by a classical hit and trial method, but state-space analysis allows us to choose the optimal range for the PI parameters in a more efficient way. By doing the statespace analysis, using the data available in Table 1, optimal range for the PI parameters can be met. Further, optimal parametric values obtained from the states-pace analysis are given in Table 2 and assessed by studying step response in the different scenarios. 


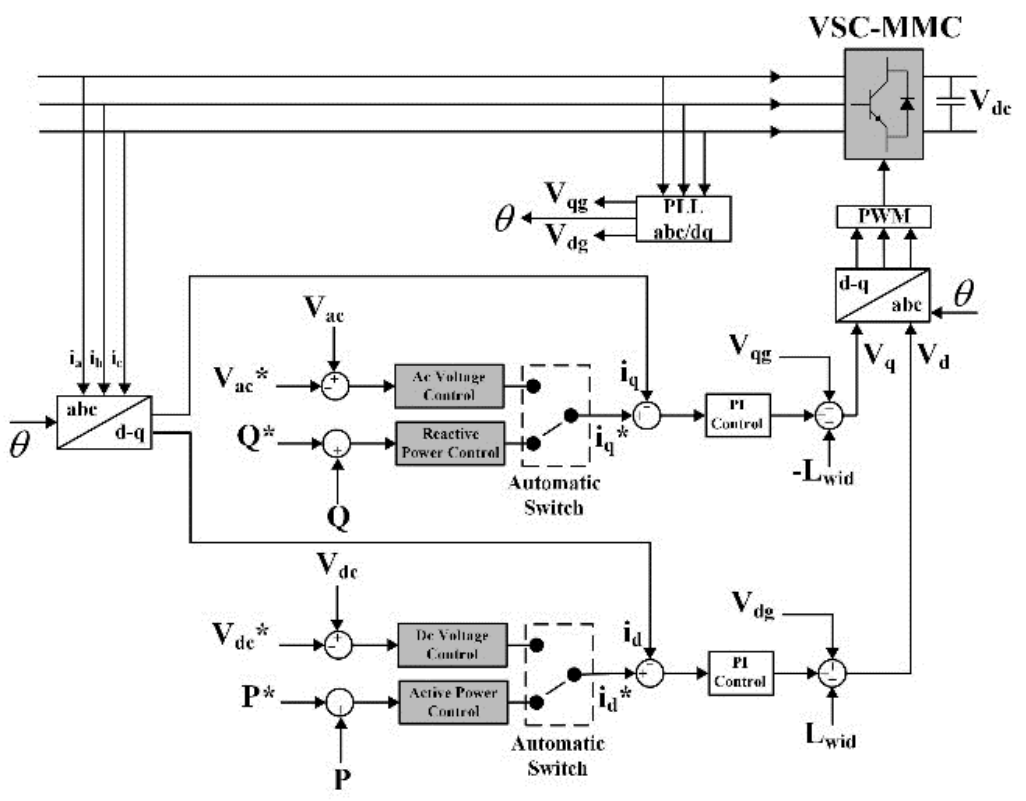

Figure 10. Dc voltage or active power and ac voltage or reactive power control for grid side MMC-VSC converters using d-q control method

\section{Simulation Results}

In this section, two different cases are discussed to analyze the state-space variables and their choice during certain states. A voltage droop control is applied at the grid sides of the system, meanwhile, off-shore windfarms inject all the power available. In this type of cases, during different scenarios, state-space variables change by examining the system and decide which voltages of the system are to be controlled in-order to optimize the control parameters.

All VSCs in the test system based on AVM technology are identical and the optimal results are implemented on all VSCs. The validity and flexibility of the proposed optimized values are assessed by simulations for two different test scenarios: change in power at wind terminal and variations of power demand by ac networks.

\section{A. Case I}

The case 1 is based on an event during which power change carried out on Wind Farm-2. In this case, simulation starts with 0.9 pu and $0.5 \mathrm{pu}$ generated by Wind Farm-1 and Wind Farm-2 respectively. In Figure. 11, at $\mathrm{t}=1 \mathrm{sec}$, Wind Farm-2 under P-Q control, increases its power generation from $0.5 \mathrm{pu}$ to $0.6 \mathrm{pu}$. Since droop control is employed at the on-shore side, VSC stations at the grid side quickly tracks the changes and acts upon it. Grid Side- 1 and Grid Side2 are two grid sides have control setting of $\mathrm{P}-\mathrm{V}_{\mathrm{ac}}$ and $\mathrm{P}-\mathrm{Q}$ respectively. $\mathrm{P}-\mathrm{V}_{\mathrm{ac}}$ control mode is used when converter terminals are attached to a weak grid and low of power is require to be constant.

Ac voltage and active power is regulated via VSC-HVdc While, P-Q control mode when converter is connected with stiff ac grid, constant power is needed. A referenced based system is assigned to reactive and active power with controlled operational modes. Since droop control is employed at the on-shore side, at $\mathrm{t}=1 \mathrm{sec}$, power of grid side one $\left(\mathrm{P}_{\text {Grid }}\right.$ Side- 1$)$ and power of grid side two $\left(\mathrm{P}_{\text {Grid }}\right.$ Side-2) change from $-0.5 \mathrm{pu}$ to $-0.55 \mathrm{pu}$ and $-0.9 \mathrm{pu}$ to $-0.95 \mathrm{pu}$ respectively due to sudden change in output power at Wind Farm-2. Furthermore, analysis of the MT-HVdc shows that Grid Side-2 absorbs generated power more than Grid Side-1. This excessive generated power is shared between two gird stations according to their voltage droop 
characteristics.

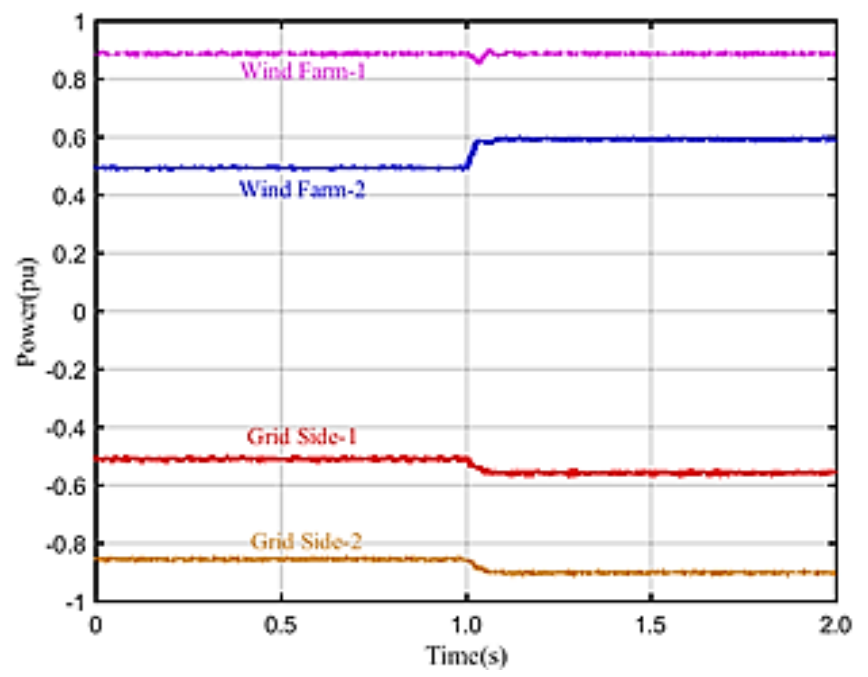

Figure 11. Effect of increase in power at the Wind Farm-2 on the on-shore terminals.

Now, for further investigation, the performance of the dc power and dc voltage is examined. For this, criteria of assessment include high-rise time and good stability margins of $P_{d c}$ and $V_{d c}$. From Figure. 11 and 12, it is established that results show significant improvements for proposed solution as compared to classical hit and trial method.

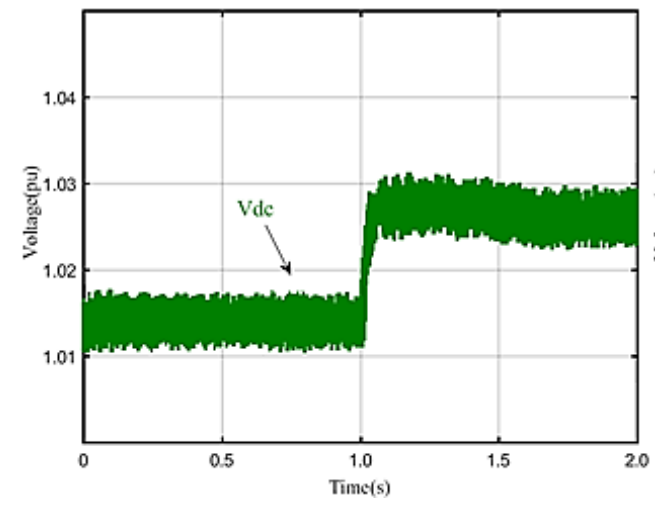

(a)

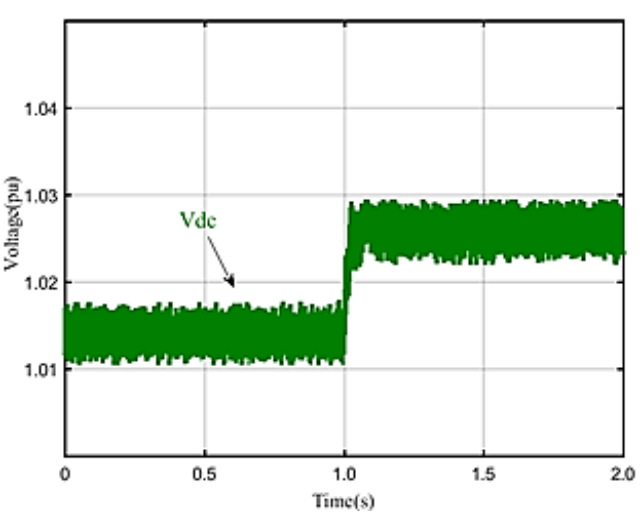

(b)

Figure 12. Voltage changes at Wind Farm-2 when its power is increased. (a) Results obtained from hit and trial method, (b) results obtained from hit and trial method

The rise time and stability margins are much improved and satisfactory at on and off-shore VSC-HVde stations.

\section{B. Case II}

In second case, simulation moves focus towards the grid side of VSC-HVdc stations. Control setting is applied at the grid side converters are P-Q and $\mathrm{P}-\mathrm{V}_{\mathrm{ac}}$ respectively. Simulation starts with the normal values, $0.8 \mathrm{pu}$ and $0.4 \mathrm{pu}$ of power generation by Wind Farm- 1 and Wind Farm2 respectively. But suddenly, Grid Side-1 power $\left(\mathrm{P}_{\text {Grid }}\right.$ Side- 1 ) changes from $-0.4 \mathrm{pu}$ to $-0.55 \mathrm{pu}$ at $\mathrm{t}=4 \mathrm{sec}$, due to sudden increase in power demand detected by the other grid side, since voltage droop is employed at the grid sides, Grid Side-2 power $\left(\mathrm{P}_{\text {Grid }}\right.$ Side-2) decreases from $-0.75 \mathrm{pu}$ to 
$-0.6 \mathrm{pu}$ respectively. The effect of power change at Grid Side- 2 can be seen in Figure. 13. $\mathrm{P}_{\mathrm{dc}}$ and $\mathrm{V}_{\mathrm{dc}}$ of the Grid Side- 1 and Grid Side- 2 show stable margin values and stay in their rated range during disturbances. Effect of power change at Grid Side-1 and Grid Side-2 on the dc voltage can be seen in Figure. 14 and 15. Proposed solution shows faster and much stable response than classical tuning method. Th dc-voltage link also settles itself within $\pm 10 \%$ suggested stabilized range [25].

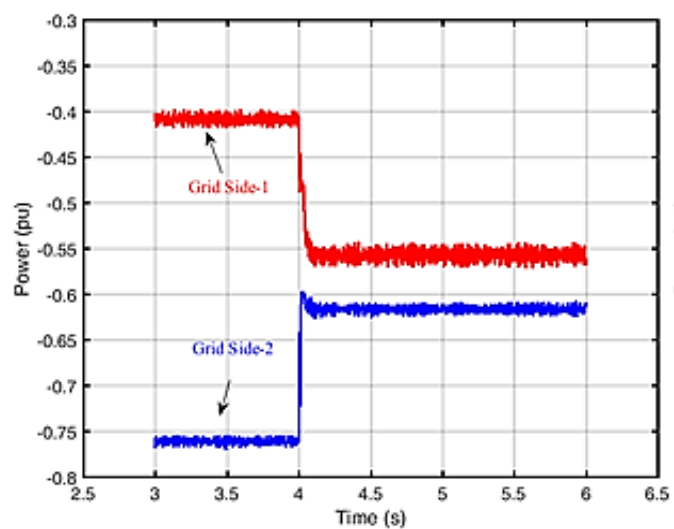

(a)

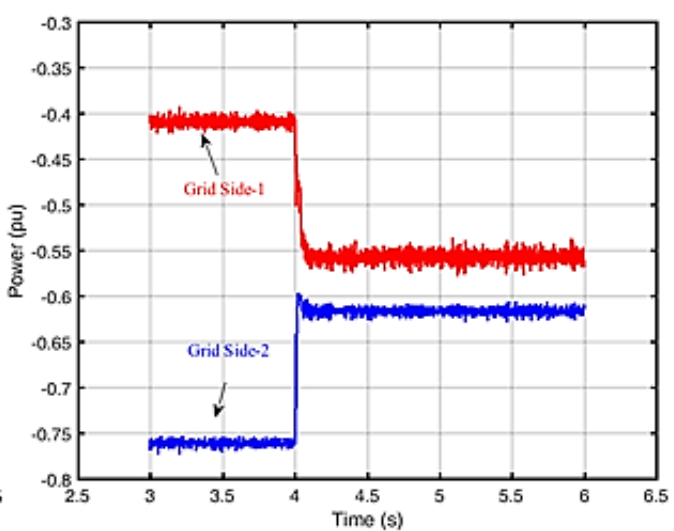

(b)

Figure 13. Power fluctuations at the Grid Side-1 and Grid Side-2. (a) Results obtained from state-space analysis, (b) results obtained from hit and trial method

Graphical representation of the results shows us that state-space analysis can enhance the response of the AVM based VSC-HVdc system. State-space analysis look at the voltage variables in the controller and helps to find optimal range for the inner and outer part of the VSC controller. Hence, improving the dynamic response under any disturbance.

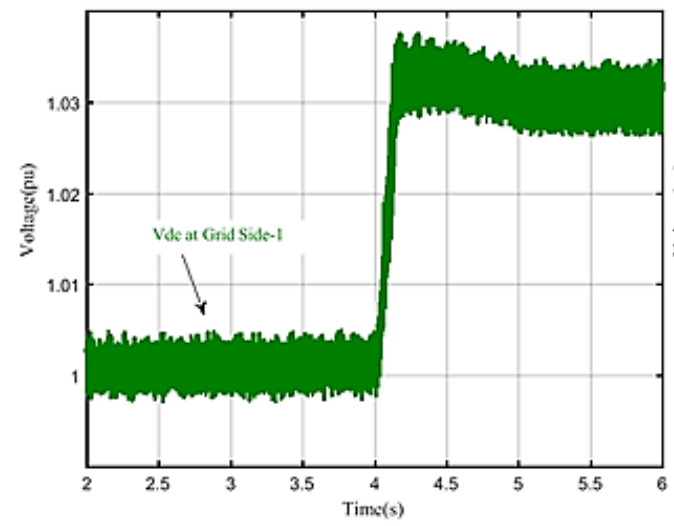

(a)

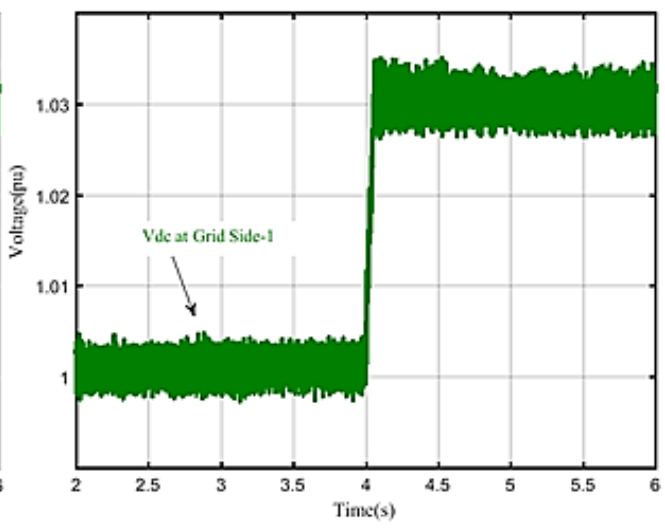

(b)

Figure 14. Effects of power change at Grid Side-1 on its de voltage (a) Results obtained from hit and trial method, (b) results obtained from state space analysis 


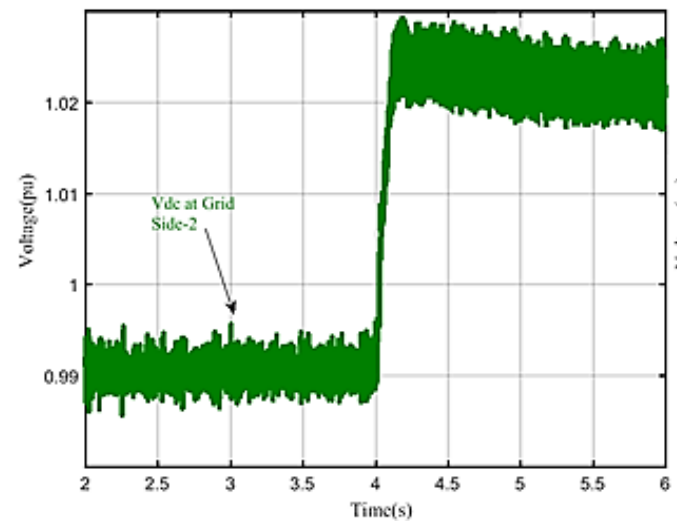

(a)

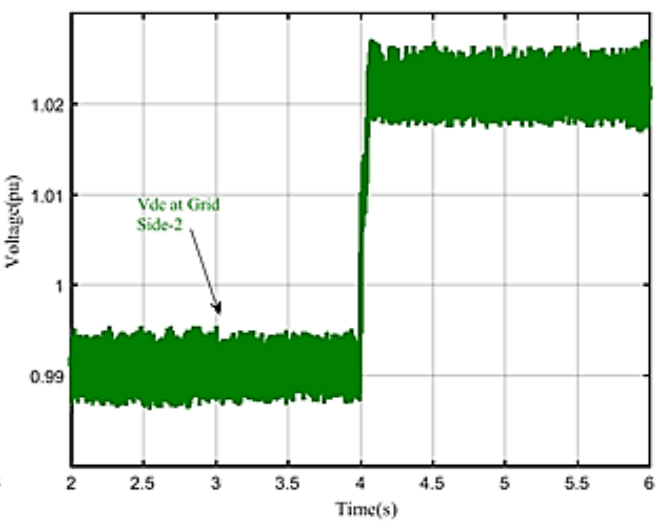

(b)

Figure 15. Effects of power change at Grid Side-2 on its dc voltage (a) Results obtained from hit and trial method, (b) results obtained from state space analysis

\section{Conclusion}

This paper focuses on the possible improvement in the control system of an average model of MMC-VSC-HVdc system using state-space analysis. The proposed solution in this paper shows that state-space analysis can improve dynamic response of the VSC-HVdc system under any disturbance. The response improved by optimizing the control limits of the AVM-VSCHVdc system. Four terminals-based test grid is designed in PSCAD to perform the simulations. Test rig is tested in two cases to understand improved dynamic responses of AVM based HVdc system using state-space analysis. First case includes change in power at wind farm side and second includes change at grid side. The results obtained are satisfactory and show improved response. However, more efforts and research should be put on non-linear behavior of MMCVSC-HVdc system, so that HVdc can become more possible and practical solution for renewable sources in future.

\section{Acknowledgment}

The authors would like to thank Dr. Ali Raza, Assistant Professor in Electrical Engineering Department of The University of Lahore, Lahore, Pakistan for his support and help in this research. The authors would also like to thank The University of Lahore, for the support.

\section{References}

[1]. E. Spahic, F. Schettler, D. Varma and J. Dorn,"Impact of the DC technology on transmission grids," 11th IET International Conference on AC and DC Power Transmission, Birmingham, 2015, pp. 1-7.

[2]. N. Flourentzou, V. G. Agelidis, and G. D. Demetriades, "VSC-Based HVdc Power Transmission Systems: An Overview”, IEEE Trans. on Power Electronics, vol. 24, no. 3, pp. 592-602, Mar. 2009.

[3]. It is Time to Connect, Technical Description of HVdc Light Technology, ABB Grid Systems - HVDC, Ludvika, Sweden, 2008.

[4]. L. Sigrist, F. Echavarren, L. Rouco and P. Panciatici,"A fundamental study on the impact of HVdc lines on transient stability of power systems," 2015 IEEE Eindhoven Power Tech, Eindhoven, 2015, pp. 1-6.

[5]. Q. Song, W. Liu, X. Li, H. Rao, S. Xu and L. Li, "A Steady-State Analysis Method for a Modular Multilevel Converter," in IEEE Transactions on Power Electronics, vol. 28, no. 8, pp. 3702-3713, Aug. 2013. 
[6]. M. Davies, M. Dommaschk, J. Dorn, J. Lang, D. Retzmann, D. Soerangr, HVdc PLUS Basics and Principle of operation, Siemens Energy Sector, E T PS SL/DSoe/Re 2008-0810 HVdc PLUS V3.

[7]. A. Lesnicar and R. Marquardt,"An innovative modular multilevel converter topology suitable for a wide power range," 2003 IEEE Bologna Power Tech Conference Proceedings, , 2003, pp. 6 pp. Vol.3.

[8]. S. Rohner, S. Bernet, M. Hiller and R. Sommer, "Modulation, Losses, and Semiconductor Requirements of Modular Multilevel Converters," in IEEE Transactions on Industrial Electronics, vol. 57, no. 8, pp. 2633-2642, Aug. 2010.

[9]. M. Hagiwara and H. Akagi, "Control and Experiment of Pulsewidth-Modulated Modular Multilevel Converters," in IEEE Transactions on Power Electronics, vol. 24, no. 7, pp. 1737-1746, July 2009.

[10]. Gemmell, J. Dorn, D. Retzmann, and D. Soerangr, "Prospects of multilevel VSC technologies for power transmission," in Proc. IEEE Transm. Distrib. Conf. Expo., Milpitas, CA, Apr. 2008, pp. 1-16.

[11]. S. R. Sanders, J. M. Noworolski, X. Z. Liu, and G. C. Verghese, "Generalized averaging method for power conversion circuits," IEEE Trans. Power Electron., vol. 6, no. 2, pp. 251-259, Apr. 1991.

[12]. S. Chiniforoosh, J. Jatskevich, A. Yazdani, V. Sood, V. Dinavahi, J. A.Martinez, and A. Ramirez, "Definitions and applications of dynamic average models for analysis of power systems," IEEE Trans. Power Del., vol. 25, no. 4, pp. 2655-2669, Oct. 2010.

[13]. P. T. Krein, J. Bentsman, R. M. Bass, and B. L. Lesieutre, "On the use of averaging for the analysis of power electronic systems," IEEE Trans. Power Electron., vol. 5, no. 2, pp. 182190, Apr. 1990.

[14]. J. Morren, S. W. H. de Haan, P. Bauer, J. Pierik, and J. Bozelie, "Comparison of complete and reduced models of a wind turbine with Doubly-fed Induction Generator," in Proc. 10th Eur. Conf. Power Electron. Appl., Toulouse, France, Sep. 2003, pp. 1-10.

[15]. J. G. Slootweg, H. Polinder, and W. L. Kling, "Representing wind turbine electrical generating systems in fundamental frequency simulations, 'IEEE Trans. Energy Convers., vol. 18, no. 4, pp. 516-524, Dec.2003.

[16]. S. R. Sanders, J. M. Noworolski, X. Z. Liu, and G. C. Verghese, Generalized averaging method for power conversion circuits,'IEEETrans. Power Electron. vol. 6, no. 2, pp. 251259, Apr. 1991.

[17]. S. Chiniforoosh,J.Jatskevich,A. Yazdani,V. Sood, V. Dinavahi, J.A. Martinez, and A. Ramirez, "Definitions and applications of dynamic average models for analysis of power systems," IEEE Trans. Power Del., vol. 25, no. 4, pp. 2655-2669, Oct. 2010.

[18]. A.Raza, M.Z.Yousaf, "Multi-Objective Optimization of VSC Stations in Multi-Terminal VSC-HVdc Grids, Based on PSO,” IEEE Open Access Journal, vol.6, pp 2169-3536, Oct.2018.

[19]. Z.L.Gaing, "A particle swarm optimization approach for optimum design of PID controller in AVR system,"' IEEE Trans. Energy Convers., vol. 19, no. 2, pp. 384-391, Jun. 2004.

[20]. A.KrohlingandJ.P.Rey, “Design of optimal disturbance rejection PID controllers using genetic algorithms,", IEEE Trans. Evol. Comput., vol. 5, no. 1, pp. 78-82, Feb. 2001.

[21]. S. R. Sanders, J. M. Noworolski, X. Z. Liu, and G. C. Verghese, "Generalized averaging method for power conversion circuits," IEEE Trans. Power Elect., vol. 6, no. 2, pp. 251259, Apr. 1991.

[22]. A. Lesnicar and R. Marquardt, "An innovative modular multilevel converter topology suitable for a wide power range," in Proc. IEEE Power Tech. Conf., Bologna, Italy, Jun. 2003. 
[23]. K. Rouzbehi, A. Miranian, A. Luna, and P. Rodriguez, “Optimized control of multiterminal DC grids using particle swarm optimization,' Eur. J. Power Electron., vol. 24, no. 2, pp. 38-49, 2014.

[24]. R. T. Pinto, P. Bauer, S. F. Rodrigues, E. J. Wiggelinkhuizen, J. Pierik, and B. Ferreira, “A novel distributed direct voltage control strategy for grid integration of offshore wind energy systems through MTDC network," IEEE Trans. Ind. Electron., vol. 60, no. 6, pp. 24292441, Jun. 2013.

[25]. J. Beerten, S. Cole, and R. Belmans, "'Modeling of multi-terminal VSC HVDC systems with distributed DC voltage control," IEEE Trans. Power Syst., vol. 29, no. 1, pp. 3442, Jan. 2014.

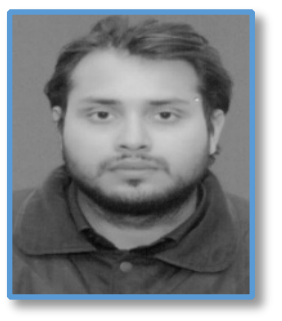

M. Zain Yousaf is pursuing his $\mathrm{PhD}$ degree from Guangxi University, China. He received his MS Electrical Engineering degree from The University of Lahore in 2018. He completed his B-Eng. Hons from Swansea University, UK in 2014. He has a teaching experience of about 3 years. His areas of interest are Power and Control Systems.

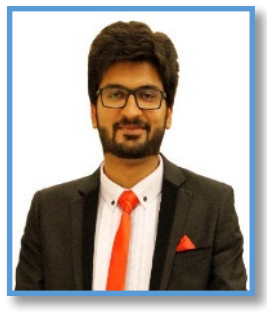

M. Arslan Shahid received his MS and BS in Electrical Engineering degrees from The University of Lahore, Pakistan in 2018 and 2015 respectively. He has got five years' experience of teaching as a Lab Engineer and Lecturer in the department of Electrical Engineering, The University of Lahore, Pakistan. His areas of interest are Power, Control Systems, Embedded Systems, Power Electronics, and AI, Deep and Machine Learnings.

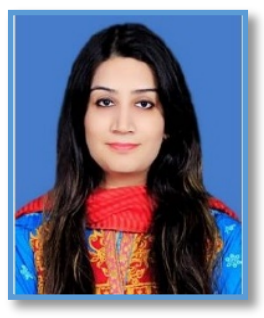

Danista Khan is pursuing her $\mathrm{PhD}$ degree from The Hong Kong Polytechnic University. She received her MSc degree in Electrical Engineering from University of Engineering and Technology in 2017. She completed her BSc in Electrical Engineering from the University of Lahore in 2013. She has got five years' experience of teaching as a Lecturer in the University of Lahore.

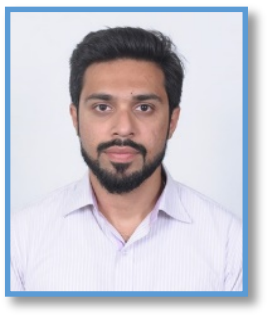

Saqib Khalid received his BS in Electrical Engineering degree from The University of Lahore, Pakistan in 2016 and is currently enrolled as a postgraduate student at The University of Lahore, Pakistan. He has got three years' experience of teaching as a Lab Engineer in the University of Lahore. His areas of research are Power engineering, particularly HVDC systems, Control Systems and Power Electronics. 